\title{
Pore-scale investigation on the response of heterotrophic respiration to moisture conditions in heterogeneous soils
}

\author{
Zhifeng Yan - Chongxuan Liu - Katherine E. Todd-Brown · Yuanyuan Liu • \\ Ben Bond-Lamberty • Vanessa L. Bailey
}

Received: 24 April 2016/ Accepted: 25 October 2016/Published online: 15 November 2016

(C) The Author(s) 2016. This article is published with open access at Springerlink.com

\begin{abstract}
The relationship between microbial respiration rate and soil moisture content is an important property for understanding and predicting soil organic carbon degradation, $\mathrm{CO}_{2}$ production and emission, and their subsequent effects on climate change. This paper reports a pore-scale modeling study to investigate the response of heterotrophic respiration to moisture conditions in soils and to evaluate various factors that affect this response. X-ray computed tomography was used to derive soil pore structures, which were then used for pore-scale model investigation. The porescale results were then averaged to calculate the effective respiration rates as a function of water content in soils. The calculated effective respiration rate first
\end{abstract}

Responsible Editor: R. Kelman Wieder.

Z. Yan · C. Liu $(\bowtie) \cdot$ K. E. Todd-Brown .

Y. Liu · V. L. Bailey

Pacific Northwest National Laboratory, 3335 Innovation

Blvd, Richland, WA 99354, USA

e-mail: Chongxuan.liu@pnnl.gov;

liucx@sustc.edu.cn

C. Liu

School of Environmental Science and Engineering, South University of Science and Technology of China,

Shenzhen, China

B. Bond-Lamberty

Pacific Northwest National Laboratory-University of Maryland Joint Global Climate Change Research Institute, College Park, MD 20740, USA increases and then decreases with increasing soil water content, showing a maximum respiration rate at water saturation degree of 0.75 , which is consistent with field and laboratory observations. The relationship between the respiration rate and moisture content is affected by various factors, including pore-scale organic carbon bioavailability, the rate of oxygen delivery, soil pore structure and physical heterogeneity, soil clay content, and microbial drought resistivity. Overall, this study provides mechanistic insights into the soil respiration response to the change in moisture conditions, and reveals a complex relationship between heterotrophic microbial respiration rate and moisture content in soils that is affected by various hydrological, geophysical, and biochemical factors.

Keywords Pore-scale Process model · Heterotrophic respiration - Moisture - Soil structure Clay content

\section{Introduction}

Moisture is one of the most important environmental factors influencing heterotrophic respiration (HR) in soils (Bond-Lamberty and Thomson 2010; Falloon et al. 2011; Moyano et al. 2013; Orchard and Cook 1983; Sierra et al. 2015). It affects soil organic carbon (SOC) bioavailability and the rate of oxygen delivery that affect microbial metabolism in regulating heterotrophic SOC decomposition (Moyano et al. 2012; 
Rodríguez-Iturbe and Porporato 2005). Low moisture content restricts pore-water connectivity and decreases SOC mass transport, and thus reduces SOC bioavailability (Davidson et al. 2012). Full saturation and inundation decreases the effective rate of oxygen diffusion and thus aerobic respiration in soils (Franzluebbers 1999; Skopp et al. 1990). Various macroscopic observations have revealed that the relationship between soil respiration rate and moisture content is complex and site-specific, depending on soil properties such as soil structure and texture (Franzluebbers 1999; Moyano et al. 2012), carbon speciation and decomposability (Bauer et al. 2008; Wang et al. 2013), and microbial activity (Lehmann et al. 2007; Manzoni et al. 2012).

Empirical models are commonly used to describe the response of microbial $\mathrm{HR}$ to moisture changes in simulating SOC degradation and carbon dioxide $\left(\mathrm{CO}_{2}\right)$ flux from soils (Bauer et al. 2008; Coleman and Jenkinson 1996; Kelly et al. 1997; Šimůnek and Suarez 1993). The prediction of carbon cycling in soils is, however, highly dependent on the empirical representations of the HR processes (Davidson et al. 2012), and contains large uncertainty (Bauer et al. 2008; Rodrigo et al. 1997; Sierra et al. 2015). Reactive transport processes including moisture-dependent diffusion for describing substrate transport and Michaelis-Menten kinetics for describing microbial respiration have been considered in the process-based models (Davidson et al. 2012). By incorporating these processes the models provide important insights into the relationship between the HR rate and moisture content (Moyano et al. 2012, 2013). However, pore-scale investigation on the effects of soil heterogeneity, SOC bioavailability, moisture content distribution, and substrate transport on soil respiration rates have not been investigated.

One reason that modeling HR remains difficult is because soils are highly heterogeneous in their geophysical and biochemical properties (Gonzalez-Polo and Austin 2009; Kuzyakov and Blagodatskaya 2015; Lehmann et al. 2007). The heterogeneous distribution of SOC and its bioavailability due to local physical protection and chemical recalcitrance (Six et al. 2002), preferential and matrix transport of substrates due to pore connectivity and local moisture content (Hunt 2004; Liu et al. 2015a, 2014; Steefel and Maher 2009), and nonuniform formation of microbial colonies and biofilms due to local substrate availability and predation inhibition (He et al. 2014; Kakumanu et al. 2013;
Or et al. 2007; Xu et al. 2014) have been observed to affect the rate of heterotrophic respiration and its correlation with moisture content in soils (Franzluebbers 1999; Moyano et al. 2012). Understanding the pore-scale physical and biochemical processes associated with these heterogeneous properties as well as their manifestations at large scales is crucial to reduce the uncertainty of predicting the relationship between HR rate and moisture content in soil systems.

This paper reports a pore-scale modeling study to establish the relationship between HR rate and moisture content in soils with heterogeneous pore structures, and evaluate the effects of various soil properties, including soil structure and texture as well as microbial drought resistivity, on this relationship. These properties influence the macroscopic soil respiration rate through affecting pore-scale physical and biochemical processes, such as organic carbon transformation and transport, oxygen diffusion and exchange, and microbial growth and decay. We hypothesize that the pore-scale modeling including these processes is able to interpret the complicated relationship of HR rate and water content observed in soils. X-ray computerized tomography and imaging analysis were used to derive pore structures for the pore-scale modeling. Only microbial HR in a root-free soil was considered in this study to provide pore-scale insights between microbial HR and moisture content.

\section{Materials and methods}

\section{Soil pore structures}

The intact soil samples collected from the US Department of Energy's Hanford Site were packed into a soil core $(10 \mathrm{~cm}$ height, $4 \mathrm{~cm}$ diameter) (Liu et al. 2015b). The samples consist of 40.7, 26.1, 17.6, and $15.6 \%$ of grains with size $<0.053 \mathrm{~mm}$, $0.053-0.5 \mathrm{~mm}, 0.5-2 \mathrm{~mm}$, and $>2 \mathrm{~mm}$, respectively. This soil core was scanned using X-ray computerized tomography (XCT, Xtek XT H 320) to obtain grayscale images at a voxel resolution of $28 \mu \mathrm{m}$ (Liu et al. 2015b). The grayscale XCT images (Fig. 1a) were digitized to derive porosity distributions (Fig. 1b, c) using a dual threshold method (Yang et al. 2014). In this method, the voxels with a grayscale value below a small threshold were assigned as a pore space (i.e., porosity $\phi=1$ ); above a large threshold 

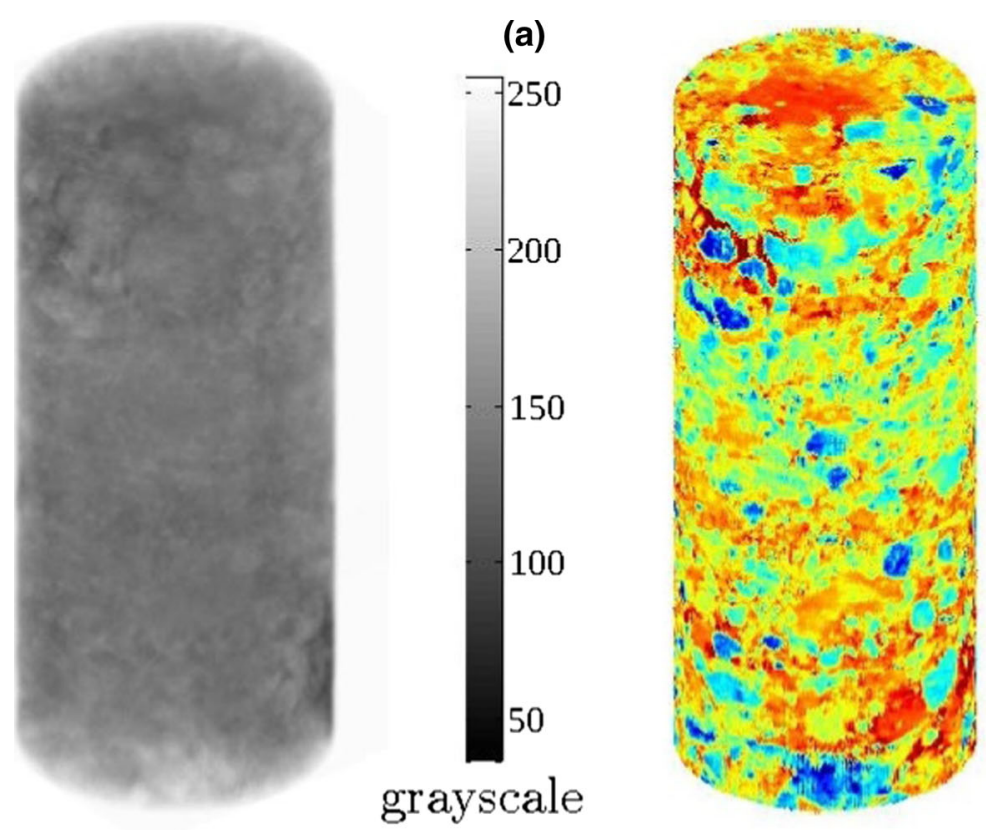

(b)

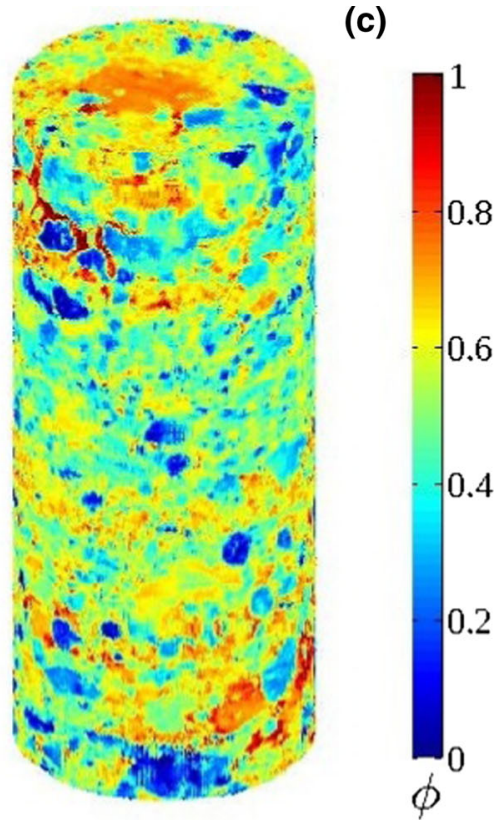

Fig. 1 a An X-ray computerized tomography image of a soil core where a larger grayscale number indicates that the voxel contains a higher content of solids; porosity $(\phi)$ distributions of soil cores with averaged porosities of $\mathbf{b} 0.58$ and $\mathbf{c} 0.5$ converted from the grayscale image. The grayscale threshold values

were assigned as a solid space (i.e., $\phi=0$ ); and values between the two thresholds were treated as spaces containing both pores and solids with porosity $(\phi)$ inversely proportional to the grayscale value. This transform method reflects the fact that some pores in soils are below the XCT resolution (i.e., $<28 \mu \mathrm{m}$ ), and voxels containing such pores have to be treated as mixed regions of pores and solids (Yang et al. 2014). The porosity for voxels with mixed pores and solids is defined in the same way as for the bulk soils, with the porosity value derived from the voxel grayscale value. The total porosity in the soil core can then be calculated by adding pore volume in each voxel. The total porosity using the transform method will depend on the two threshold values, which were determined by matching the calculated total porosity to the measured bulk porosity in the soil (Yang et al. 2014).

Three soil cores with different degrees of heterogeneity and porosity values were used to evaluate the effects of soil structure on the relationship between heterotrophic respiration and moisture. The first and second cores were constructed using the XCT images (Fig. 1a), and have heterogeneous pore structures with different average porosity values of 0.58 (Fig. 1b) and applied for the conversion were 85 and 200 for (b) and 77 and 190 for (c). For the porosity distribution, 0 denotes solid, 1 denotes pore, and other values between them denote regions with mixed pores and solids

0.5 (Fig. 1c), which are nearly the averaged porosities of the natural and compressed soil cores, respectively, as reported in a reference (Franzluebbers 1999). This was realized by changing the grayscale threshold values in converting the XCT grayscale images to porosity distribution. The third core was artificially created, and has the same average porosity as that in the first core, but all voxels are assumed to have the same properties (homogeneous and porosity 0.58 ).

\section{Model description}

Important processes that can potentially affect respiration rates were considered in the model simulations. These processes include soil organic carbon partitioning between dissolved and sorbed phases, microbial metabolism of SOC as carbon source and electron donor, and oxygen $\left(\mathrm{O}_{2}\right)$ and $\mathrm{CO}_{2}$ diffusion and partitioning in gas and liquid phases. The transformation of SOC from sorbed to dissolved organic carbon (DOC) was described using a first-order kinetic model to account for the mass transfer process limiting the bioavailability of the SOC associated with the intraaggregate domains (Jardine et al. 1989). Microbial 
metabolism and respiration rate were described using the dual Michaelis-Menten kinetic model with respect to DOC and dissolved oxygen (DO). The $\mathrm{CO}_{2}$ produced by respiration forms various dissolved inorganic carbon species which were assumed to be in local equilibrium with gas phase $\mathrm{CO}_{2}$ using Henry's law (Sander 2015). The gas phase $\mathrm{CO}_{2}$ was allowed to release into atmosphere through the top surface of the soil core. The dissolved and gaseous $\mathrm{O}_{2}$ were also assumed to be at local equilibrium following Henry's law, and were supplied through diffusion in both liquid and gas phases from the top of the soil core where they are in equilibrium with atmospheric $\mathrm{O}_{2}$. With these treatments, the heterotrophic respiration and reactive transport of dissolved and gaseous species in soils can be described using the following equations:

$$
\begin{aligned}
& \frac{\partial C_{D O C}}{\partial t}-\nabla \cdot\left(D_{D O C} \nabla C_{D O C}\right) \\
& =\rho_{s}(1-\phi) \frac{k_{m}}{\theta}\left(C_{S O C}-K_{C} C_{D O C}\right) A \\
& \quad-k_{D O C} \alpha C_{B} \frac{C_{D O C}}{C_{D O C}+K_{D O C}} \frac{C_{D O}}{C_{D O}+K_{D O}},
\end{aligned}
$$

$\frac{\partial C_{S O C}}{\partial t}=-k_{m}\left(C_{S O C}-K_{c} C_{D O C}\right) A$,

$\frac{\partial C_{B}}{\partial t}=Y k_{D O C} \alpha C_{B} \frac{C_{D O C}}{C_{D O C}+K_{D O C}} \frac{C_{D O}}{C_{D O}+K_{D O}}-k_{B} C_{B}$,

$$
\begin{aligned}
& \frac{\partial\left(\theta C_{D O}+\varepsilon C_{G O}\right)}{\partial t}-\theta \nabla \cdot\left(D_{D O} \nabla C_{D O}\right)-\varepsilon \nabla \cdot\left(D_{G O} \nabla C_{G O}\right) \\
& =-\theta v_{D O} k_{D O C} \alpha C_{B} \frac{C_{D O C}}{C_{D O C}+K_{D O C}} \frac{C_{D O}}{C_{D O}+K_{D O}},
\end{aligned}
$$

$$
\begin{aligned}
& \frac{\partial\left(\theta C_{D I C}+\varepsilon C_{G I C}\right)}{\partial t}-\theta \nabla \cdot\left(D_{D I C} \nabla C_{D I C}\right)-\varepsilon \nabla \cdot\left(D_{G I C} \nabla C_{G I C}\right) \\
& =\theta v_{D I C} k_{D O C} \alpha C_{B} \frac{C_{D O C}}{C_{D O C}+K_{D O C}} \frac{C_{D O}}{C_{D O}+K_{D O}}
\end{aligned}
$$

$C_{D O}=K_{h, o} C_{G O}$,

$C_{D I C}=K_{p H} K_{h, c} C_{G I C}$,

where $C_{D O C}$ is the DOC concentration $(\mathrm{g} / \mathrm{l}), C_{S O C}$ is the concentration of sorbed organic carbon (g/g soil), $C_{B}$ is the concentration of microbial biomass $(\mathrm{g} / \mathrm{l})$,
$C_{D O}$ is the DO concentration $(\mathrm{g} / \mathrm{l}), C_{G O}$ is the concentration of gaseous oxygen $(\mathrm{g} / \mathrm{l}), C_{D I C}$ is the concentration of dissolved inorganic carbon (DIC) (g/ 1), $C_{G I C}$ is the concentration of gaseous $\mathrm{CO}_{2}(\mathrm{~g} / \mathrm{l}), \rho_{s}$ is the soil particle (solid) density $\left(\mathrm{kg} / \mathrm{m}^{3}\right), \phi$ is the local soil porosity for each numerical voxel (-), $\theta$ is the local water content $\left(\mathrm{m}^{3} / \mathrm{m}^{3}\right), k_{m}$ is the mass transfer coefficient of soil organic carbon $(\mathrm{m} / \mathrm{s}), K_{c}$ is the adsorption/desorption equilibrium constant of DOC (1/ $\mathrm{g}), A$ is the specific surface area of soil solid materials $\left(\mathrm{m}^{2} / \mathrm{m}^{3}\right), \quad k_{D O C}$ is the maximum rate of DOC metabolism (g DOC/g biomass/s), $\alpha$ is the fraction of active microbes (-), $K_{D O C}$ is the half-rate coefficient with respect to DOC $(\mathrm{g} / \mathrm{l}), K_{D O}$ is the half-rate coefficient with respect to DO $(\mathrm{g} / \mathrm{l}), Y$ is the yield coefficient of biomass (g biomass/g DOC), $k_{B}$ is the first order decay coefficient of biomass $(1 / \mathrm{s}), \varepsilon$ is the local air content $(\varepsilon=\phi-\theta), v_{D O}$ is the stoichiometric coefficient of DO consumption per gram of DOC decomposition (g DO/g DOC), $v_{D I C}$ is the stoichiometric coefficient of DIC production per gram of DOC decomposition (g DIC/g DOC), $D_{D O C}$ is the effective diffusion coefficient of DOC $\left(\mathrm{m}^{2} / \mathrm{s}\right), D_{D O}$ is the effective diffusion coefficient of DO $\left(\mathrm{m}^{2} / \mathrm{s}\right), D_{G O}$ is the effective diffusion coefficient of gaseous $\mathrm{O}_{2}\left(\mathrm{~m}^{2} /\right.$ s), $D_{D I C}$ is the effective diffusion coefficient of DIC $\left(\mathrm{m}^{2} / \mathrm{s}\right), D_{G I C}$ is the effective diffusion coefficient of gaseous $\mathrm{CO}_{2}\left(\mathrm{~m}^{2} / \mathrm{s}\right), K_{h, o}$ is the Henry constant for $\mathrm{O}_{2}$ $(-), K_{h, c}$ is the Henry constant for $\mathrm{CO}_{2}(-)$, and $K_{p H}$ is a coefficient related to equilibrium reactions of DIC species and $\mathrm{pH}$ value:

$K_{p H}=1+\frac{K_{a 1}}{\left[H^{+}\right]}+\frac{K_{a 1} K_{a 2}}{\left[H^{+}\right]^{2}}$,

where $K_{a 1}$ and $K_{a 2}$ are the two equilibrium carbonic acid speciation constants $\left(\mathrm{mole} / \mathrm{m}^{3}\right)$ (Stumm and Morgan 1996).

The diffusivity of dissolved and gaseous species in soils is dependent on the saturation degree as well as pore water and pore air connectivity (Moldrup et al. 2001). In this study, this dependency is described using the following equations (Archie 1942; Hunt 2004),

$$
\frac{D_{D}}{D_{D, 0}}=\left(\phi-\theta_{\mathrm{th}}\right)^{m 1}\left(\frac{\theta-\theta_{\mathrm{th}}}{\phi-\theta_{\mathrm{th}}}\right)^{n 1},
$$


$\frac{D_{G}}{D_{G, 0}}=\phi^{m 2}\left(\frac{\varepsilon-\varepsilon_{\mathrm{th}}}{\phi-\varepsilon_{\mathrm{th}}}\right)^{n 2}$,

where $D_{D}$ and $D_{G}$ are the effective diffusion coefficients of dissolved species $\left(\mathrm{m}^{2} / \mathrm{s}\right)\left(\right.$ e.g., $D_{D O C}, D_{D O}$, and $D_{D I C}$ in Eqs. $1,4,5)$ and gaseous species $\left(\mathrm{m}^{2} / \mathrm{s}\right)\left(\right.$ e.g., $D_{G O}$ and $D_{G I C}$ in Eqs. 4,5$)$, respectively; $D_{D, 0}$ and $D_{G, O}$ are the corresponding diffusion coefficients in pure water and air $\left(\mathrm{m}^{2} / \mathrm{s}\right)$, respectively; $\theta_{\mathrm{th}}$ is the water percolation threshold $\left(\mathrm{m}^{3} / \mathrm{m}^{3}\right)$, below which water is disconnected and the effective solute diffusion coefficient becomes zero; $\varepsilon_{\mathrm{th}}$ is the gas percolation threshold $\left(\mathrm{m}^{3} / \mathrm{m}^{3}\right)$, below which air is disconnected and gas phase diffusion ceases; $m 1$ and $m 2$ are cementation exponents (-); $n 1$ and $n 2$ are saturation exponent (-). $m 1, n 1$ and $m 2, n 2$ are empirical parameters accounting for the effect of tortuosity and pore connectivity on aqueous and gas phases diffusion, respectively, in heterogeneous soils (Ghanbarian and Hunt 2014; Hamamoto et al. 2010).

The percolation threshold in Eq. 9 can be estimated using the following equation (Bear 1972; Hamamoto et al. 2010):

$\theta_{\mathrm{th}}=a_{\theta} \rho_{b}\left(\frac{C C}{2.7}+C_{S O C}\right)$,

where $C C$ is clay content $(\mathrm{g} / \mathrm{g})$ (Moldrup et al. 2007), $\rho_{b}$ is soil bulk density $\left(\mathrm{kg} / \mathrm{m}^{3}\right), \rho_{b}=\rho_{s}(1-\phi)$, and $a_{\theta}$ is an empirical coefficient (-). The gas percolation threshold in Eq. 10 can be estimated using the following equation (Ghanbarian and Hunt 2014; Hamamoto et al. 2010):

$\varepsilon_{\text {th }}=a_{\varepsilon} \phi$,

where $a_{\varepsilon}$ is an empirical coefficient related to soil texture (-) (Hunt 2004).

The mass transfer coefficient, $k_{m}$, for soil organic carbon in Eqs. 1 and 2 was estimated based on the measured diffusivity of dissolved organic carbon in unsaturated porous media (Conca and Wright 1990; Cussler 2009):

$k_{m}=\frac{\theta^{p}}{K_{\theta}+\theta} \alpha D_{D O C, 0}$

where $K_{\theta}$ is a saturation constant $\left(\mathrm{m}^{3} / \mathrm{m}^{3}\right), p$ is an exponent determining the change rate of $k_{m}$ as $\theta$ changes, and $\alpha$ is a parameter reflecting the desorption rate of $\operatorname{SOC}(1 / \mathrm{m})$. Their values depend on soil structure and texture, organic carbon speciation, and carbon-mineral association.
Moisture content can affect microbial survival and activities (Manzoni et al. 2012). As soils dry, osmotic pressure on microorganism surfaces can affect microbial activities, and may force a fraction of microorganisms into dormancy (Manzoni et al. 2014). The fraction of active microbes can be described by (Manzoni et al. 2014):

$\alpha=\frac{\left(-K_{\psi}\right)^{\omega}}{(-\psi)^{\omega}+\left(-K_{\psi}\right)^{\omega}}$,

where $\psi$ is water potential $(\mathrm{MPa}), K_{\psi}$ is the water potential when microbes reach $50 \%$ of the maximum activity (MPa), and $\omega$ is an empirical parameter (-). A larger absolute $K_{\psi}$ value means stronger microbial resistance against drought, and a larger $\omega$ means a more abrupt response of microbial activity to drought. The effect of microbial resistance to drought on respiration rate was assessed by varying parameters $K_{\psi}$ and $\omega$ in this study. A relationship $\psi=$ $-0.00055\left(\frac{\theta}{\phi}\right)^{-3.58}$ was used to link the water content to water potential (Franzluebbers 1999).

\section{Parameters and numerical procedures}

Most parameter values and simulation conditions (Table 1) used in the modeling were from literature cited in Table 1. Only the values of parameters in Eq. 13 were fitted by experimental data. The temperature and $\mathrm{pH}$ value were assumed constant during the simulations.

The initial sorbed organic carbon is assumed to be proportional to solid mass fraction in each numerical voxel. The sorbed organic carbon is allowed to desorb to become DOC following Eq. 2. A measured microbe concentration was used as the initial biomass concentration (Lin et al. 2012). The initial concentrations of the gaseous phase $\mathrm{O}_{2}$ and $\mathrm{CO}_{2}$ in soils were assumed to be in equilibrium with atmospheric values under 1 atm and $25^{\circ} \mathrm{C}$. The initial concentration of dissolved $\mathrm{O}_{2}$ and $\mathrm{CO}_{2}$ were assumed in equilibrium with gases phase $\mathrm{O}_{2}$ and $\mathrm{CO}_{2}$ following Henry's law. Since the top surface of the soil core was connected to the atmosphere, the concentrations of $\mathrm{O}_{2}$ and $\mathrm{CO}_{2}$ were fixed on this top boundary (Dirichlet-type boundary condition). A no flux (Neumann-type) boundary condition was applied to other boundaries. 
Table 1 Parameter and initial values used in the modeling study

\begin{tabular}{|c|c|c|c|c|}
\hline Symbol & Description & Value & Units & Sources and notes \\
\hline$D_{D O C, 0}$ & Diffusion coefficient of DOC & $1.9 \times 10^{-10}$ & $\mathrm{~m}^{2} / \mathrm{s}$ & Hendry et al. (2003) \\
\hline$D_{D O, 0}$ & Diffusion coefficient of DO & $2.1 \times 10^{-9}$ & $\mathrm{~m}^{2} / \mathrm{s}$ & Cussler (1997) \\
\hline$D_{G O, 0}$ & Diffusion coefficient of gaseous $\mathrm{O}_{2}$ & $2.1 \times 10^{-5}$ & $\mathrm{~m}^{2} / \mathrm{s}$ & Weast (1997) \\
\hline$D_{D I C, 0}$ & Diffusion coefficient of DIC & $1.92 \times 10^{-9}$ & $\mathrm{~m}^{2} / \mathrm{s}$ & Cussler (1997) \\
\hline$D_{G I C, 0}$ & Diffusion coefficient of gaseous $\mathrm{CO}_{2}$ & $1.92 \times 10^{-5}$ & $\mathrm{~m}^{2} / \mathrm{s}$ & Weast (1997) \\
\hline$k_{D O C}$ & Maximum reaction rate of DOC & $1.97 \times 10^{-5}$ & $\begin{array}{l}\text { g DOC/g } \\
\text { biomass/s }\end{array}$ & Borden and Bedient (1986) \\
\hline$v_{D O}$ & Stoichiometric coefficient of DO & 2.45 & g DO/g DOC & Calculated (Yang et al. 2014) \\
\hline$v_{D I C}$ & Stoichiometric coefficient of DIC & 3.43 & $\mathrm{~g} \mathrm{DIC/g} \mathrm{DOC}$ & Calculated (Yang et al. 2014) \\
\hline$Y$ & Yield coefficient & 0.5 & $\begin{array}{l}\mathrm{g} \text { biomass } / g \\
\text { DOC }\end{array}$ & Borden and Bedient (1986) \\
\hline$k_{b}$ & Decay rate & $1.16 \times 10^{-7}$ & $1 / \mathrm{s}$ & Borden and Bedient (1986) \\
\hline$K_{D O C}$ & Half-saturation coefficient of DOC & $1.3 \times 10^{-4}$ & $\mathrm{~g} / 1$ & Borden and Bedient (1986) \\
\hline$K_{D O}$ & Half-saturation coefficient of DO & $1.0 \times 10^{-4}$ & $\mathrm{~g} / 1$ & Borden and Bedient (1986) \\
\hline$\rho_{s}$ & Soil density & $2.65 \times 10^{3}$ & $\mathrm{~kg} / \mathrm{m}^{3}$ & Franzluebbers (1999) \\
\hline$C C$ & Clay content & 0.2 & $\mathrm{~g} / \mathrm{g}$ & Franzluebbers (1999) \\
\hline$a_{\theta}$ & $\begin{array}{l}\text { Empirical coefficient for water percolation } \\
\text { threshold }\end{array}$ & 0.2 & - & $\begin{array}{l}\text { Franzluebbers (1999) and } \\
\text { Moyano et al. (2013) }\end{array}$ \\
\hline$a_{\varepsilon}$ & $\begin{array}{l}\text { Empirical coefficient for air percolation } \\
\text { threshold }\end{array}$ & 0.1 & - & Hunt (2004) \\
\hline$K_{c}$ & Equilibrium constant & 0.039 & $1 / \mathrm{g}$ & Jardine et al. (1989) \\
\hline$A$ & Soil specific surface area & $3.01 \times 10^{7}$ & $\mathrm{~m}^{2} / \mathrm{m}^{3}$ & Leão and Tuller (2014) \\
\hline$p$ & Exponent & 1 & - & Fitted \\
\hline$K_{\theta}$ & Saturation constant & 0.1 & $\mathrm{~m}^{3} / \mathrm{m}^{3}$ & Fitted \\
\hline$\alpha$ & Empirical parameter & $3.07 \times 10^{-6}$ & $1 / \mathrm{m}$ & Fitted \\
\hline$m 1$ & Cementation exponent & 1.5 & - & Moyano et al. (2013) \\
\hline$n 1$ & Saturation exponent & 2 & - & Moyano et al. (2013) \\
\hline$m 2$ & Cementation exponent & 1.5 & - & Moyano et al. (2013) \\
\hline$n 2$ & Saturation exponent & 2.5 & - & Moyano et al. (2013) \\
\hline$K_{\alpha 1}$ & $\begin{array}{l}\text { Equilibrium constant between carbonic acid and } \\
\text { bicarbonate }\end{array}$ & $10^{-6.3}$ & $\mathrm{~mol} / \mathrm{m}^{3}$ & Stumm and Morgan (1996) \\
\hline$K_{\alpha 2}$ & $\begin{array}{l}\text { Equilibrium constant between bicarbonate and } \\
\text { carbonate }\end{array}$ & $10^{-10.25}$ & $\mathrm{~mol} / \mathrm{m}^{3}$ & Stumm and Morgan (1996) \\
\hline$C_{S O C, 0}$ & Initial concentration of sorbed organic carbon & 0.02 & $\mathrm{~g} / \mathrm{g}$ & Franzluebbers (1999) \\
\hline$C_{D O C, 0}$ & Initial concentration of DOC & 0.0 & $\mathrm{~g} / \mathrm{g}$ & Assumed \\
\hline$C_{B, 0}$ & Initial concentration of biomass & $5 \times 10^{-5}$ & $\mathrm{~g} / \mathrm{g}$ & Lin et al. (2012) \\
\hline$C_{D O, 0}$ & Initial concentration of DO & $8.3 \times 10^{-3}$ & $\mathrm{~g} / 1$ & Colt (2012) \\
\hline$C_{G O, 0}$ & Initial concentration of gaseous $\mathrm{O}_{2}$ & 0.2609 & $\mathrm{~g} / 1$ & Wallace and Hobbs (1977) \\
\hline$C_{D I C, 0}$ & Initial concentration of DIC & $2.93 \times 10^{-3}$ & $\mathrm{~g} / 1$ & Colt (2012) \\
\hline$C_{G I C, 0}$ & Initial concentration of gaseous $\mathrm{CO}_{2}$ & $7.91 \times 10^{-4}$ & $\mathrm{~g} / 1$ & Wallace and Hobbs (1977) \\
\hline$K_{h, o}$ & Henry constant for $\mathrm{O}_{2}$ & $3.181 \times 10^{-2}$ & - & Sander (2015) \\
\hline$K_{h, c}$ & Henry constant for $\mathrm{CO}_{2}$ & 0.2137 & - & Sander (2015) \\
\hline$K_{\psi}$ & Half-saturation coefficient of microbial activity & 0.4 & MPa & Manzoni et al. (2014) \\
\hline$\omega$ & Empirical parameter & 1 & - & Manzoni et al. (2014) \\
\hline$T$ & Temperature & 25 & ${ }^{\circ} \mathrm{C}$ & Assumed \\
\hline $\mathrm{pH}$ & $\mathrm{pH}$ value & 6.8 & - & Assumed \\
\hline
\end{tabular}


An in-house implicit, finite-volume method code written in Fortran was developed to solve the governing equations (Eqs. 1-5). For each step a successive over-relaxation (SOR) method was used to iterate the algebraic equations derived from Eqs. 1-5, with a convergence criterion of $10^{-10}$ (Ferziger and Perić 1999). To linearize equations in this method, DOC concentration in the denominator of the last term in Eq. 1 was calculated using the DOC concentration at the current time step. The same approach was used for linearizing the equation for DO (Eq. 4).

\section{Results and discussion}

Model calibration

Simulated and measured results were first compared to evaluate the effectiveness of the pore-scale model (Eqs. 1-5) in simulating HR rate as a function of saturation degree $S$ (Fig. 2), the relative water-filled pore space $(S=\theta / \phi)$ used to represent the degree of soil saturation in this study. The measured data in Fig. 2 were from literature where soil samples were incubated in canning jars under different saturation conditions (Franzluebbers 1999). This literature reported the responses of soil respiration rate to

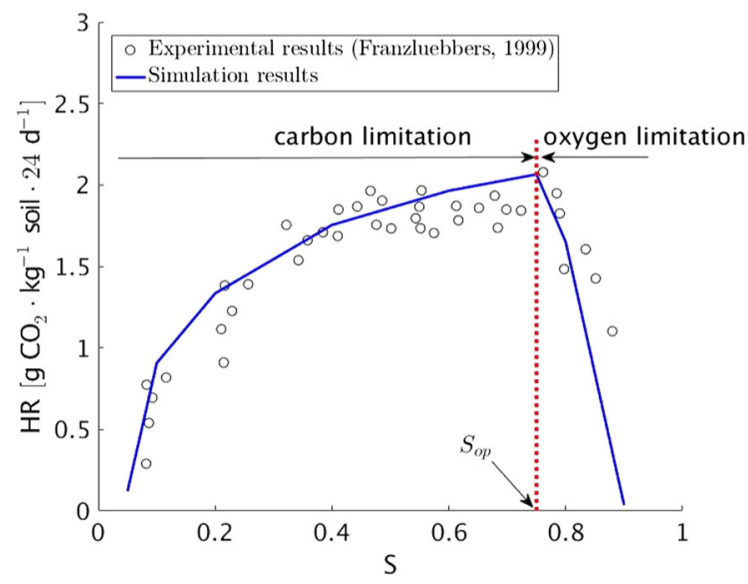

Fig. 2 Soil heterotrophic respiration (HR) rate as a function of saturation degree (S) after 24 days of incubation. The experimental respiration rates were measured from different soil cores with a mean porosity of 0.58 (Franzluebbers 1999). The simulation results were the averaged respiration rates calculated by the pore-scale respiration rates for each voxel in the heterogeneous soil core with average porosity of 0.58 as shown in Fig. 1 saturation degree for natural soils with different clay contents, soil organic carbon contents, and bulk densities. Since the optimal water saturation for maximum respiration rate did not change consistently with the variance in clay content and the effects of soil organic carbon content and porosity were uncertain in the experiments, the measured respiration rates under different saturation degrees for all natural soils were used to calibrate the pore-scale model. The values of clay content, soil organic carbon content, and porosity used in the pore-scale simulations were the averaged values for the natural soils. The simulated HR rates, which were averaged pore-scale rates over the soil core, agree well with the measured values (Fig. 2), indicating that the macroscopic phenomenon of $\mathrm{HR}$ rate as a function of moisture content can be simulated using the pore-scale model. The minor discrepancies between the simulated and experimental results are expected, since the soil core used in the simulations is not the one used in the experiment. Figure 2 shows that the HR rate first increases and then decreases with increasing degree of saturation, with the largest HR rate occurring at a saturation degree, $S_{o p}$, near 0.75 .

From the pore-scale point of view, the increase in HR rate with increasing saturation degree when $S$ is below $S_{o p}$ is because the local mass transfer rate of soil organic carbon from sorbed to dissolved phases increases with moisture content (Eq. 13), which subsequently increases the pore-scale concentration of dissolved organic carbon and the rate of carbon degradation (Eq. 1). The effects of increasing moisture content on organic carbon (OC) mass transfer rate become less important at higher moisture content as the water in most pore spaces becomes connected (Eq. 13). This results in a decreasing slope of the HRS curve with increasing degree of saturation (Fig. 2). In addition, the increase in moisture content reduces the gas phase diffusion coefficient of $\mathrm{O}_{2}$ (Eq. 10). Although the increase in moisture content would increase the aqueous phase diffusion coefficient of $\mathrm{O}_{2}$ (Eq. 9), the aqueous phase diffusion is much slower (Table 1). Consequently, the overall rate of $\mathrm{O}_{2}$ diffusion decreases with increasing moisture content. This decrease in $\mathrm{O}_{2}$ diffusion rate results in the decrease in the rate of HR (Eq. 1).

At the saturation degree of $S_{o p}$, the negative effect of $\mathrm{O}_{2}$ limitation cancels the positive effect of OC bioavailability on the HR rate. When the saturation degree is over $S_{o p}$, the effect of $\mathrm{O}_{2}$ limitation 
dominates the effect of OC bioavailability, thus the HR rate decreases as the saturation degree further increases (Fig. 2). The gas phase oxygen diffusion decreases dramatically once air connectivity approaches the threshold value $(S=0.9)$. Consequently, the HR rate decreases dramatically from the largest value at $S_{o p}$. The oxygen diffusion in aqueous phase is significantly slow such that most locations in the soils lack $\mathrm{O}_{2}$ and the average $\mathrm{HR}$ rate is nearly zero (anaerobic respiration was not considered in this study).

During the simulations only the parameters in Eq. 13 were fitted to match the experimental data. These parameters primarily determine the maximum respiration rate and the shape of the HR-S curve at the left side (i.e., carbon limitation side in Fig. 2) through changing the bioavailability of DOC. The different maximum respiration rates and HR-S curves observed in laboratories and field sites indicate that the relation between organic carbon transfer rate and water content changes with soils (Daly et al. 2009; Falloon et al. 2011; Skopp et al. 1990).

When comparing the simulation results with experimental data, the averaged HR respiration rates calculated from the pore-scale simulations were fitted to the measured $\mathrm{CO}_{2}$ efflux at the top of canning jars in the experiment under assumption that the biogenic $\mathrm{CO}_{2}$ was not accumulated inside the soil. This may be not true under high saturation degree (Daly et al. 2009; Kim et al. 2012), when the produced $\mathrm{CO}_{2}$ can be accumulated inside soils because of the low diffusion rate of gaseous $\mathrm{CO}_{2}$ (Eq. 10). Another uncertainty is that the pore structure for the pore-scale simulations was derived from the XCT images under an assumption that two grayscale threshold values were enough to transfer grayscale images to pore structure. When multiple threshold values exist, the two threshold value method would bias the pore structure and thus simulation results. Although various approaches have been proposed to reduce the error caused by the conversion between grayscale value and pore structure, uncertainty exists inevitably (Wildenschild and Sheppard 2013).

Effect of soil structure on heterotrophic respiration rate

Figure 3 shows the effects of soil structure on the relationship between soil HR and saturation. The HR

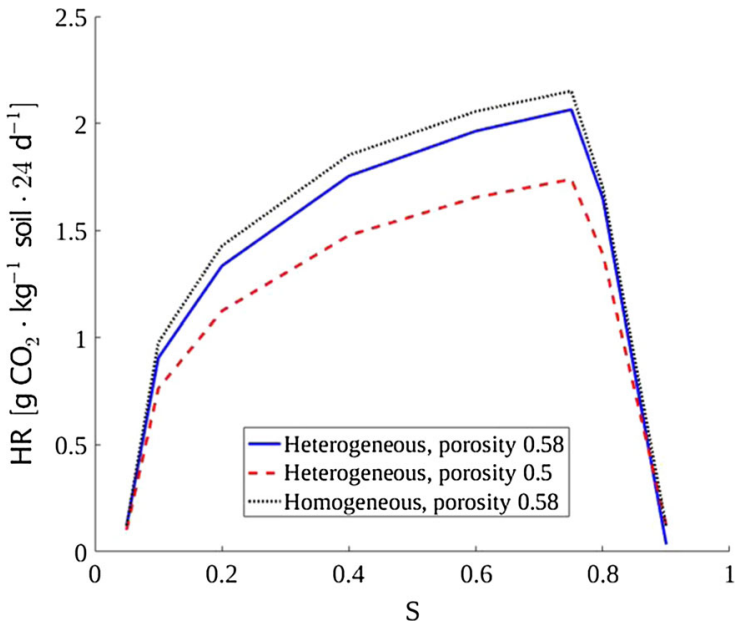

Fig. 3 Effects of soil porosity and structure on simulated soil heterotrophic respiration (HR) rate as a function of saturation degree (S)

is faster in the soils with a larger average porosity and is slower in soils with heterogeneous structure. The faster HR rate in the soils with a higher porosity is because of the faster oxygen diffusion in the soils due to the better pore connectivity (Eq. 9) and the faster release of OC from the sorbed phase as the rate of OC release is assumed to be proportional to the water content (Eqs. 2 and 13). This result has been observed in the laboratory experiments where compressed soils produced less carbon decomposition than the natural ones (Franzluebbers 1999). The slower HR rate in the soils with a heterogeneous structure is because OC at those locations with poor pore connectivity is either difficult to access by microorganisms or $\mathrm{O}_{2}$ is limited by diffusion, even though these pores are in theory bioaccessible. By contrast, in the homogeneous soil all $\mathrm{OC}$ is equally accessible to microorganisms and the $\mathrm{O}_{2}$ diffusion is relatively fast. Among the three cores, the one with porosity 0.5 and a heterogeneous structure shows the slowest HR rate as a result of limitation of OC bioavailability and slow pore phase diffusion of $\mathrm{O}_{2}$ in poorly connected pore regions.

Pore structure affects substrate diffusion in soils not only through porosity $\phi$ but also pore connectivity manifested by the values of parameters $m 1$ and $n 1$ in Eqs. 9. Sensitivity analyses were conducted to evaluate the impact of $m 1$ and $n 1$ on HR rate. Simulation results show that changes in $m 1$ and $n 1$ values for aqueous phase diffusion (Eq. 9) have little impact on soil HR (results not shown). This is because $\mathrm{O}_{2}$ 
diffusion in aqueous phase has minimal effect on HR rate and OC are mainly degraded locally in this study. The finding is consistent with the observation where bacterial utilization of soil organic carbon is limited by short-distance transport process (Ekschmitt et al. 2008). In contrast, Fig. 4 shows the change in $m 2$ and $n 2$ values for gas phase diffusion (Eq. 10) alters the HR-S curve at the right side (i.e., oxygen limitation side in Fig. 2), because oxygen diffusion in gas phase is the main pathway to provide necessary electron acceptor for OC oxidation. Smaller $m 2$ and $n 2$ values promote soil respiration by increasing the oxygen diffusion rate, although this promotion is not significant.
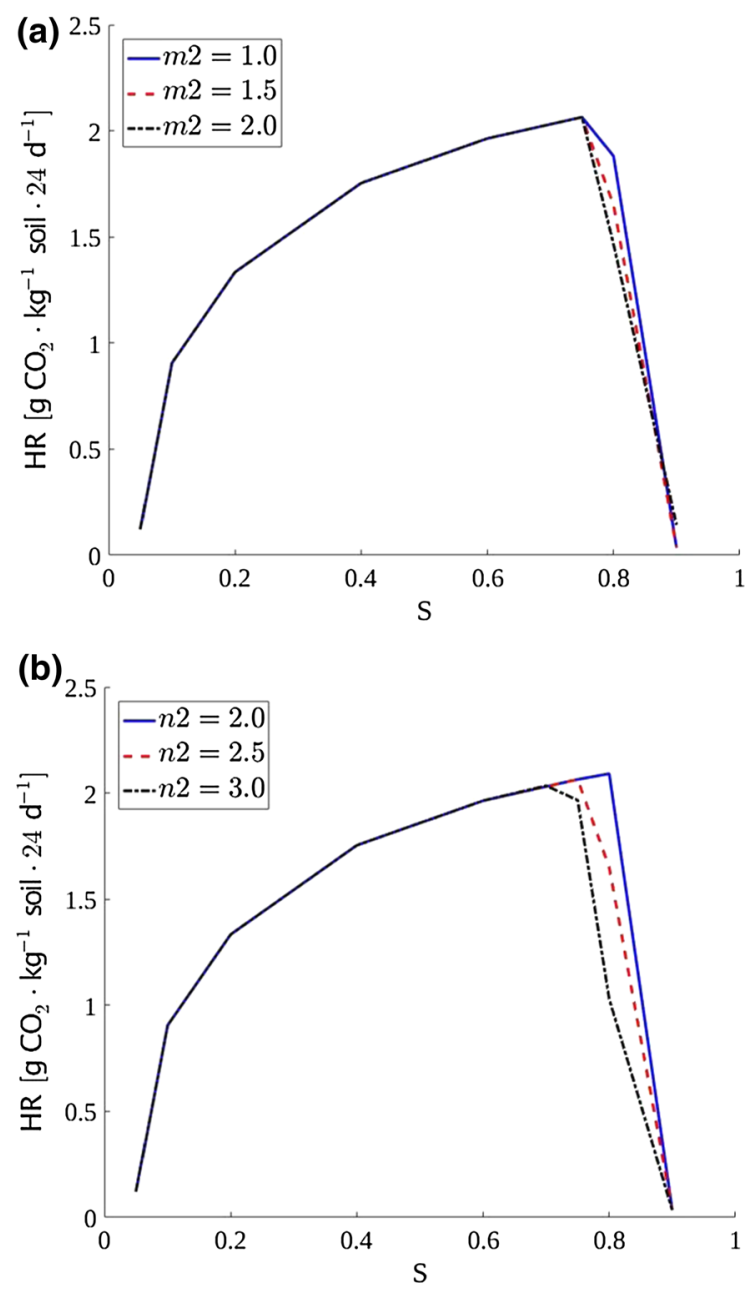

Fig. 4 Effects of a cementation exponent $m 2$, and $\mathbf{b}$ saturation exponent $n 2$ on the relationship between simulated soil heterotrophic respiration (HR) and saturation degree (S). The results shown in the figure are for the heterogeneous soil core with porosity 0.58
Effect of soil texture on heterotrophic respiration rate

Soil texture is another important factor to affect soil HR process by affecting substrate availability (Thomsen et al. 1999), microbial community structure (Or et al. 2007), and water retention capacity (Moyano et al. 2012). In this study, the clay content in soils was used to assess how soil texture might affect soil respiration rate. High clay content might impede the transport of substrates in soils by limiting pore phase diffusion and advection (Bear 1972) and decrease OC bioavailability by decreasing its mass transfer from aggregated regions to microbe-residing pore locations (Six et al. 2002). These factors will decrease the rate of microbial respiration. On the other hand, a soil with a higher clay content typically has a larger specific surface area $A$ (Eqs. 1 and 2) that may enhance OC desorption from sorbed carbon (Kögel-Knabner et al. 2008), thus increasing HR rate.

In the modeling, the effect of clay content on HR rate is through its effect on the percolation threshold of water and air, which influences the diffusion of dissolved organic carbon and oxygen. The water threshold, $\theta_{\text {th }}$, controls the formation of water films and connection, thus affecting transport of dissolved substrates. The simulation results indicated that $\theta_{\text {th }}$ had little impact on soil respiration in this study (results not shown) because dissolved oxygen supplied is through gas phase diffusion, and aqueous diffusion is negligible as described above. The air threshold, $\varepsilon_{\mathrm{th}}$, on the other hand, significantly affects soil HR at high degree of saturation when $\mathrm{O}_{2}$ limits the $\mathrm{HR}$ rate (Fig. 5). Figure 5 shows that a smaller $a_{\varepsilon}$, which leads to a smaller percolation threshold, extends the HR-S curve toward a larger saturation condition. The result is expected because a smaller gas percolation threshold increases the effective air connectivity and thus $\mathrm{O}_{2}$ diffusion rate.

The water threshold also affects the effective water content in soils that is vital for microbial activity. As the clay fraction increases, the relative amount of small pores such as those in aggregates and matrix increases. This leads to a relative increase in the amount of pore water associated with these small pore regions in soils because of capillary restriction. This part of the pore space, however, cannot be accessed by microbes because of pore size limitations. This would effectively reduce the amount of water-associated 


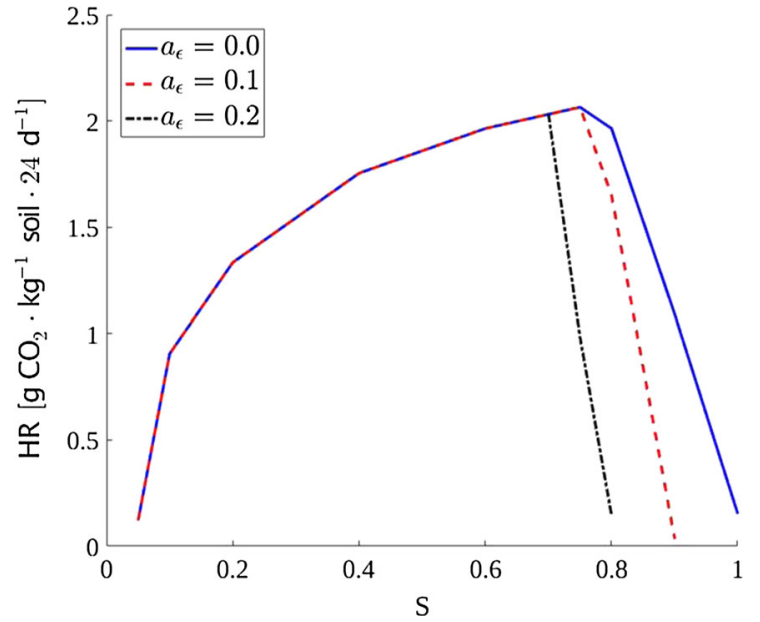

Fig. 5 Effects of air percolation threshold, $\varepsilon_{\mathrm{th}}=a_{\varepsilon} \phi$, on the relationship between simulated soil heterotrophic respiration (HR) and saturation degree (S). The results are for the heterogeneous soil core with porosity 0.58

pore spaces for microbial activity, decrease overall OC bioavailability as the fraction of $\mathrm{OC}$ associated with clay particles becomes inaccessible to microorganisms, and thus reduce the overall rate of microbial degradation of OC in soils. Simulation results (Fig. 6) demonstrate that the soil HR rate decreases with increasing clay content as a result of the decrease in OC bioavailability. This decrease diminishes at high degree of saturation because oxygen, rather than OC

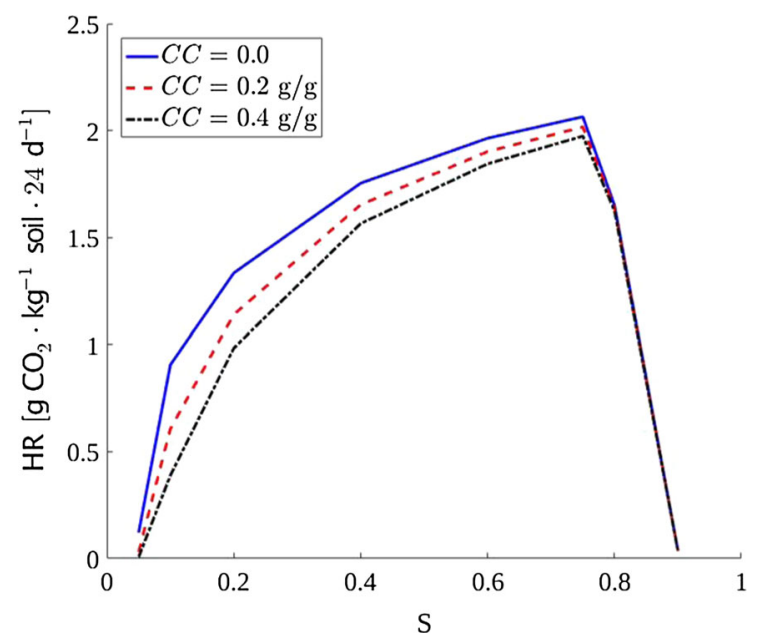

Fig. 6 Effects of clay content (CC) on the relationship between simulated soil heterotrophic respiration (HR) and saturation degree $(S)$. The results are for the heterogeneous soil core with porosity 0.58 bioavailability, limits the respiration rate under highly saturated conditions.

The soil specific surface area, $A$, has a large effect on the relationship between soil HR rate and saturation degree (Fig. 7). Soil HR rate increases significantly with increasing $A$ when the soil respiration occurs at the OC limitation side. On the other hand, a large surface area, thereby a high carbon bioavailability, results in a low optimal saturation for maximum respiration rate (Fig. 7), which is consistent with the field observation where carbon-rich soils induced a lower optimal saturation than soils with low carbon content (Moyano et al. 2013).

Clay content affects both effective water content in the pore regions for microbial activities and the soil surface area. The results (Figs. 6,7) indicated that the specific surface area has a stronger effect on the soil respiration rate as compared with the effective water content. These two factors are, however, coupled in their effects on the HR respiration rate. If the large surface area is only associated with the aggregate regions, its effect on the HR rate would be diminished because mass transfer processes limit the bioavailability of $\mathrm{OC}$ associated with the interior of the aggregate regions. The $\mathrm{OC}$ inside the aggregate regions may be quickly desorbed locally, but will not become bioavailable until it diffuses out of the aggregate regions. The complicated effects of clay content might explain the inconsistent change of soil

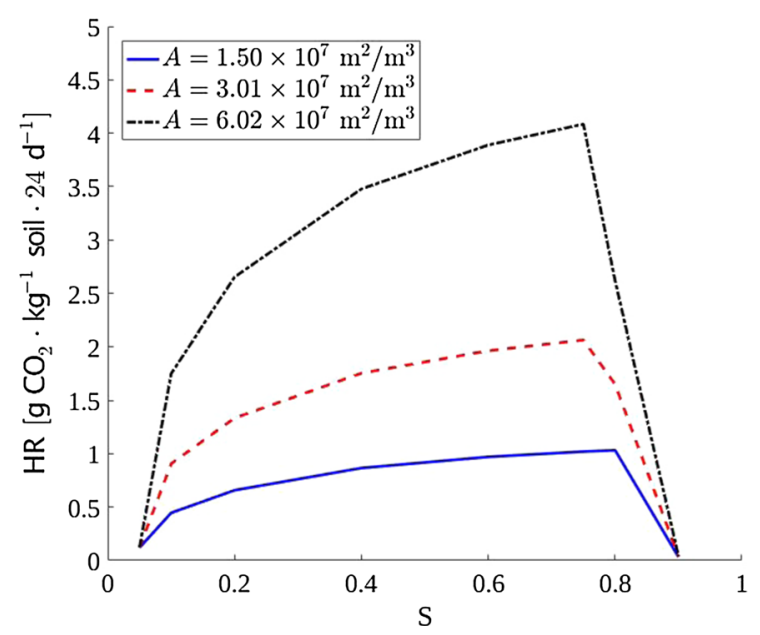

Fig. 7 Effects of soil specific surface area $(A)$ on the relationship between soil heterotrophic respiration (HR) and saturation degree $(\mathrm{S})$. The results are for the heterogeneous soil core with porosity 0.58 
respiration rate as clay content increased in experiment (Franzluebbers 1999) and the wide range of optimal saturation for maximum respiration rates in laboratory and field observations (Franzluebbers 1999; Daly et al. 2009; Moyano et al. 2012).

Effect of microbial activity on heterotrophic respiration rate

The function in Eq. 14 was first calibrated against an observed bacterial survival rate with respect to drought stress by adjusting parameters $K_{\psi}$ and $\omega$ (Freckman 1986). The best fitted values are $K_{\psi}=1$ MPa and $\omega=4$ with the fitted result shown in Fig. 8a.
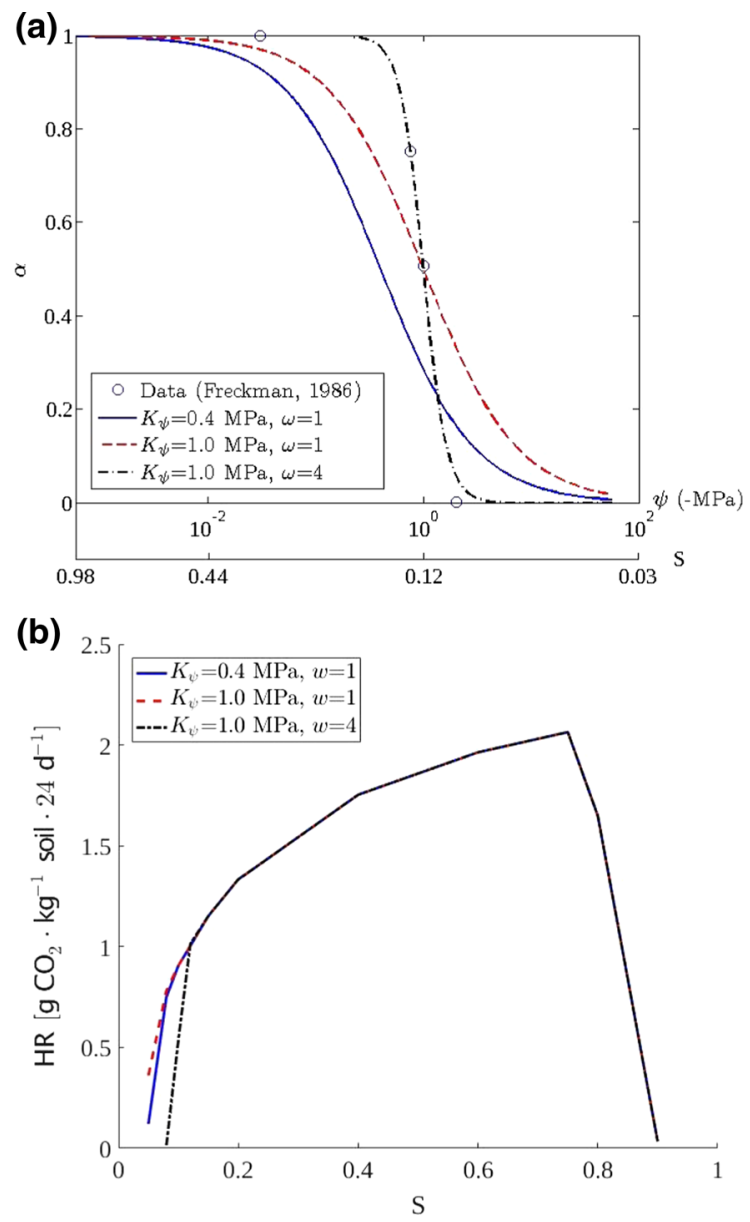

Fig. 8 a Calculated fraction of active microbes $(\alpha)$ as a function of water potential $\psi$ (or saturation degree $S$ ) for the three microbe species with different $K_{\psi}$ and $\omega$; b simulated soil heterotrophic respiration (HR) rate as a function of saturation degree $(\mathrm{S})$ in soils dominated by three different microbe species. The results are for the heterogeneous soil core with porosity 0.58
These parameter values were then varied to assess the sensitivity of microbial survival ability under drought stress. Different microorganisms have different levels of resistance to drought stress (Manzoni et al. 2012). By varying these parameters, the model can simulate the survival rate of different microorganisms (Fig. 8a). The effect of microbial survival rate on the soil respiration rate in response to drought stress, as expected, primarily occurs in the low saturation degree region $(S<12 \%)$ (Fig. 8 b). Above $12 \%$ in saturation degree, the survival rate is high (Fig. 8a), and has minimal effect on overall microbial activities. The fast drop in the respiration rate for the case with $K_{\psi}=1 \mathrm{MPa}$ and $\omega=4$ as compared to other two cases with more drought-tolerant representations (Fig. 8b) is because of the fast drop in the microbial survival rate (Fig. 8a) as the saturation degree decreases below $12 \%$.

Under drought condition microorganisms might use other strategies to survive, such as osmotic adjustment which requires sufficient substrate (Manzoni et al. 2014; Warren 2014). Nevertheless, due to the limited carbon availability under low degree of saturation, switching to dormancy in this study seems an effective way for microbes resisting against drought.

\section{Conclusions and implications}

The relationship between soil heterotrophic respiration rate and moisture content is a fundamental property for understanding and modeling organic carbon cycling in soils (Falloon et al. 2011; Sierra et al. 2015; Vincent et al. 2006). Various experimental studies have been performed to understand mechanistic processes and factors controlling such a relationship (Franzluebbers 1999; Kakumanu et al. 2013; Schjønning et al. 1999; Thomsen et al. 1999; Vincent et al. 2006). In this study, we used a pore-scale modeling approach to investigate this problem and to provide pore-scale insights into the relationship between soil HR rate and moisture content. The pore-scale approach has advantages, in particular that mechanism-based processes can be directly incorporated in the modelling. This allows evaluating the effect of individual process and their coupling. Assessing the effects of all these processes through experimental measurements is often time consuming and sometimes challenging in designing experimental 
systems (Moyano et al. 2012; Thomsen et al. 1999). In this regard, the numerical studies as presented in this study represent a cost-effective approach for investigating carbon mineralization in soils. The simulation results generally confirmed the phenomenon that the soil respiration rate is a function of moisture content, and produced emergent results that were consistent with field and laboratory observational studies.

Our results showed that the effective respiration rate can be affected by various factors, including porescale OC bioavailability, oxygen delivery, soil structure, soil texture and microbial drought resistivity. Among all evaluated factors, the bioavailability of OC and the delivery of oxygen are two most important factors affecting the effective soil respiration rate as a function of moisture content. Generally, the soil respiration rate is controlled by the $\mathrm{OC}$ bioavailability under low saturation conditions and the delivery of oxygen limit under high saturation conditions. Other factors such as soil structures including porosity, air and water filled pore connectivity, and pore structure heterogeneity, and soil texture (aggregate content, pore water distribution, and OC protection in aggregate regions) affect the soil HR rate through their effects on OC bioavailability and oxygen delivery. In addition, this study found that the survival rate of microorganisms in response to drought stress can affect HR rate when the saturation degree is below $12 \%$.

This research indicates that increasing porosity can effectively improve diffusion of substrates through soils, and thereby promotes HR rate. The results implied that consolidation and porosity decrease in fields can reduce $\mathrm{OC}$ degradation rate and improve the protection of $\mathrm{OC}$ in soils. The results of this study also indicated that a higher water content leads to a lower HR rate due to the restriction of oxygen delivery in gas phase, consistent with both theoretical expectations and many previous observations. This result implied that a wet environment in soil facilitates OC protection and slows HR rate. This conclusion, however, may change when anaerobic processes are included in the modeling, which were not considered in the simulations. Further research is needed to evaluate the effect of coupled aerobic and anaerobic processes on OC degradation.

Acknowledgements This research was supported by the US Department of Energy (DOE) Biological and Environmental
Research (BER) Division through the Terrestrial Ecosystem Science (TES) program (Grant Number 61512). Part of the research was performed at Environmental Molecular Science Laboratory (EMSL), a DOE National user facility located at Pacific Northwest National Laboratory (PNNL). PNNL is operated by Battelle Memorial Institute under subcontract DEAC06-76RLO 1830. Dr. Todd-Brown is grateful for support given by the Linus Pauling Distinguished Postdoctoral Fellowship, a Laboratory Directed Research program at PNNL. We thank the associate editor and two anonymous reviewers whose insightful comments improved the manuscript substantially.

Open Access This article is distributed under the terms of the Creative Commons Attribution 4.0 International License (http:// creativecommons.org/licenses/by/4.0/), which permits unrestricted use, distribution, and reproduction in any medium, provided you give appropriate credit to the original author(s) and the source, provide a link to the Creative Commons license, and indicate if changes were made.

\section{References}

Archie GE (1942) The electrical resistivity log as an aid in determining some reservoir characteristics. Trans AIME 146(01):54-62

Bauer J, Herbst M, Huisman JA, Weihermüller L, Vereecken H (2008) Sensitivity of simulated soil heterotrophic respiration to temperature and moisture reduction functions. Geoderma 145(1-2):17-27

Bear J (1972) Dynamics of fluids in porous media. Dover, Mineola

Bond-Lamberty B, Thomson A (2010) Temperature-associated increases in the global soil respiration record. Nature 464(7288):579-582

Borden RC, Bedient PB (1986) Transport of dissolved hydrocarbons influenced by oxygen-limited biodegradation: 1 . Theoretical development. Water Resour Res 22(13):19731982

Coleman K, Jenkinson DS (1996) RothC-26.3 - a model for the turnover of carbon in soil. In: Powlson D, Smith P, Smith J (eds) Evaluation of soil organic matter models. NATO ASI Series. Springer, Berlin, pp 237-246

Colt J (2012) Front-matter. In: Colt J (ed) Computation of dissolved gas concentration in water as functions of temperature, salinity and pressure, 2nd edn. Elsevier, London

Conca JL, Wright J (1990) Diffusion coefficients in gravel under unsaturated conditions. Water Resour Res 26(5):10551066

Cussler EL (1997) Diffusion. Cambridge University Press, Cambridge

Cussler EL (2009) Diffusion: mass transfer in fluid systems. Cambridge University Press, Cambridge

Daly E, Palmroth S, Stoy P, Siqueira M, Oishi AC, Juang J-Y, Oren R, Porporato A, Katul G (2009) The effects of elevated atmospheric $\mathrm{CO}_{2}$ and nitrogen amendments on subsurface $\mathrm{CO}_{2}$ production and concentration dynamics in a maturing pine forest. Biogeochemistry 94(3):271-287 
Davidson EA, Samanta S, Caramori SS, Savage K (2012) The Dual Arrhenius and Michaelis-Menten kinetics model for decomposition of soil organic matter at hourly to seasonal time scales. Glob Chang Biol 18(1):371-384

Ekschmitt K, Kandeler E, Poll C, Brune A, Buscot F, Friedrich M, Gleixner G, Hartmann A, Kastner M, Marhan S (2008) Soil-carbon preservation through habitat constraints and biological limitations on decomposer activity. Z Pflanzenernahr Bodenkd 171(1):27

Falloon P, Jones CD, Ades M, Paul K (2011) Direct soil moisture controls of future global soil carbon changes: an important source of uncertainty. Glob Biogeochem Cycles. doi:10.1029/2010GB003938

Ferziger JH, Perić M (1999) Computational methods for fluid dynamics. Springer, Berlin

Franzluebbers AJ (1999) Microbial activity in response to water-filled pore space of variably eroded southern Piedmont soils. Appl Soil Ecol 11(1):91-101

Freckman DW (1986) The ecology of dehydration in soil organisms. In: Leopold AC (ed) Membranes, metabolism and dry organisms. Cornell University Press, Ithaca

Ghanbarian B, Hunt AG (2014) Universal scaling of gas diffusion in porous media. Water Resour Res 50(3):2242-2256

Gonzalez-Polo M, Austin AT (2009) Spatial heterogeneity provides organic matter refuges for soil microbial activity in the Patagonian steppe, Argentina. Soil Biol Biochem 41(6): 1348-1351

Hamamoto S, Moldrup P, Kawamoto K, Komatsu T (2010) Excluded-volume expansion of Archie's law for gas and solute diffusivities and electrical and thermal conductivities in variably saturated porous media. Water Resour Res. doi:10.1029/2009WR008424(6)

He Y, Zhuang Q, Harden JW, McGuire AD, Fan Z, Liu Y, Wickland KP (2014) The implications of microbial and substrate limitation for the fates of carbon in different organic soil horizon types of boreal forest ecosystems: a mechanistically based model analysis. Biogeosciences 11(16):4477-4491

Hendry MJ, Ranville JR, Boldt-Leppin BEJ, Wassenaar LI (2003) Geochemical and transport properties of dissolved organic carbon in a clay-rich aquitard. Water Resour Res. doi:10.1029/2002WR001943

Hunt AG (2004) Continuum percolation theory for water retention and hydraulic conductivity of fractal soils: estimation of the critical volume fraction for percolation. Adv Water Resour 27(2):175-183

Jardine PM, McCarthy JF, Weber NL (1989) Mechanisms of dissolved organic carbon adsorption on soil. Soil Sci Soc Am J 53(5):1378-1385

Kakumanu ML, Cantrell CL, Williams MA (2013) Microbial community response to varying magnitudes of desiccation in soil: a test of the osmolyte accumulation hypothesis. Soil Biol Biochem 57:644-653

Kelly RH, Parton WJ, Crocker GJ, Graced PR, Klír J, Körschens M, Poulton PR, Richter DD (1997) Simulating trends in soil organic carbon in long-term experiments using the century model. Geoderma 81(1-2):75-90

Kim DG, Vargas R, Bond-Lamberty B, Turetsky MR (2012) Effects of soil rewetting and thawing on soil gas fluxes: a review of current literature and suggestions for future research. Biogeosciences 9(7):2459-2483
Kögel-Knabner I, Guggenberger G, Kleber M, Kandeler E, Kalbitz K, Scheu S, Eusterhues K, Leinweber P (2008) Organo-mineral associations in temperate soils: integrating biology, mineralogy, and organic matter chemistry. J Plant Nutr Soil Sci 171(1):61-82

Kuzyakov Y, Blagodatskaya E (2015) Microbial hotspots and hot moments in soil: concept \& review. Soil Biol Biochem 83:184-199

Leão TP, Tuller M (2014) Relating soil specific surface area, water film thickness, and water vapor adsorption. Water Resour Res 50(10):7873-7885

Lehmann J, Kinyangi J, Solomon D (2007) Organic matter stabilization in soil microaggregates: implications from spatial heterogeneity of organic carbon contents and carbon forms. Biogeochemistry 85(1):45-57

Lin X, Kennedy D, Peacock A, McKinley J, Resch CT, Fredrickson J, Konopka A (2012) Distribution of microbial biomass and potential for anaerobic respiration in hanford site 300 area subsurface sediment. Appl Environ Microb 78(3):759-767

Liu C, Shang J, Shan H, Zachara JM (2014) Effect of subgrid heterogeneity on scaling geochemical and biogeochemical reactions: a case of U (VI) desorption. Environ Sci Technol 48(3):1745-1752

Liu C, Liu Y, Kerisit S, Zachara J (2015a) Pore-scale process coupling and effective surface reaction rates in heterogeneous subsurface materials. Rev Miner Geochem 80:191216

Liu Y, Liu C, Kukkadapu RK, McKinley JP, Zachara J, Plymale AE, Miller MD, Varga T, Resch CT (2015b) 99Tc(VII) retardation, reduction, and redox rate Scaling in naturally reduced sediments. Environ Sci Technol 49(22):1340313412

Manzoni S, Schimel JP, Porporato A (2012) Responses of soil microbial communities to water stress: results from a metaanalysis. Ecology 93(4):930-938

Manzoni S, Schaeffer SM, Katul G, Porporato A, Schimel JP (2014) A theoretical analysis of microbial eco-physiological and diffusion limitations to carbon cycling in drying soils. Soil Biol Biochem 73:69-83

Moldrup P, Olesen T, Komatsu T, Schjønning P, Rolston DE (2001) Tortuosity, diffusivity, and permeability in the soil liquid and gaseous phases. Soil Sci Soc Am J 65(3):613623

Moldrup P, Olesen T, Blendstrup H, Komatsu T, de Jonge LW, Rolston DE (2007) Predictive-descriptive models for gas and solute diffusion coefficients in variably saturated porous media coupled to pore-size distribution: IV. Solute diffusivity and the liquid phase impedance factor. Soil Sci 172(10):741-750

Moyano FE, Vasilyeva N, Bouckaert L, Cook F, Craine J, Curiel Yuste J, Don A, Epron D, Formanek P, Franzluebbers A, Ilstedt U, Kätterer T, Orchard V, Reichstein M, Rey A, Ruamps L, Subke JA, Thomsen IK, Chenu C (2012) The moisture response of soil heterotrophic respiration: interaction with soil properties. Biogeosciences 9(3):11731182

Moyano FE, Manzoni S, Chenu C (2013) Responses of soil heterotrophic respiration to moisture availability: an exploration of processes and models. Soil Biol Biochem 59:72-85 
Or D, Smets BF, Wraith JM, Dechesne A, Friedman SP (2007) Physical constraints affecting bacterial habitats and activity in unsaturated porous media: a review. Adv Water Resour 30(6-7):1505-1527

Orchard VA, Cook FJ (1983) Relationship between soil respiration and soil moisture. Soil Biol Biochem 15(4):447-453

Rodrigo A, Recous S, Neel C, Mary B (1997) Modelling temperature and moisture effects on $\mathrm{C}-\mathrm{N}$ transformations in soils: comparison of nine models. Ecol Model 102(2-3): 325-339

Rodríguez-Iturbe I, Porporato A (2005) Ecohydrology of watercontrolled ecosystems: soil moisture and plant dynamics. Cambridge University Press, Cambridge

Sander R (2015) Compilation of Henry's law constants (version 4.0) for water as solvent. Atmos Chem Phys 15(8):43994981

Schjønning P, Thomsen IK, Møberg JP, de Jonge H, Kristensen K, Christensen BT (1999) Turnover of organic matter in differently textured soils: I. Physical characteristics of structurally disturbed and intact soils. Geoderma 89(3-4): 177-198

Sierra CA, Trumbore SE, Davidson EA, Vicca S, Janssens I (2015) Sensitivity of decomposition rates of soil organic matter with respect to simultaneous changes in temperature and moisture. J Adv Model Earth Syst 7(1):335-356

Šimůnek J, Suarez DL (1993) Modeling of carbon dioxide transport and production in soil: 1. Model developmen. Water Resour Res 29(2):487-497

Six J, Conant RT, Paul EA, Paustian K (2002) Stabilization mechanisms of soil organic matter: implications for C-saturation of soils. Plant Soil 241(2):155-176

Skopp J, Jawson MD, Doran JW (1990) Steady-state aerobic microbial activity as a function of soil water content. Soil Sci Soc Am J 54(6):1619-1625

Steefel CI, Maher K (2009) Fluid-rock interaction: a reactive transport approach. In: Oelkers EH, Schott J (eds)
Thermodynamics and kinetics of water-rock interaction. Reviews in mineralogy \& geochemistry. Mineralogical Society of America, Chantilly, pp 485-532

Stumm W, Morgan JJ (1996) Aquatic chemistry: chemical equilibria and rates in natural waters. Wiley, Hoboken

Thomsen IK, Schjønning P, Jensen B, Kristensen K, Christensen BT (1999) Turnover of organic matter in differently textured soils: II. Microbial activity as influenced by soil water regimes. Geoderma 89(3-4):199-218

Vincent G, Shahriari AR, Lucot E, Badot P-M, Epron D (2006) Spatial and seasonal variations in soil respiration in a temperate deciduous forest with fluctuating water table. Soil Biol Biochem 38(9):2527-2535

Wallace JM, Hobbs PV (1977) Atmospheric science: an introductory survey. Academic Press, Cambridge

Wang H, Liu S, Wang J, Shi Z, Lu L, Guo W, Jia H, Cai D (2013) Dynamics and speciation of organic carbon during decomposition of leaf litter and fine roots in four subtropical plantations of China. For Ecol Manag 300:43-52

Warren CR (2014) Response of osmolytes in soil to drying and rewetting. Soil Biol Biochem 70:22-32

Weast RC (1997) CRC handbook of chemistry and physics. CRC Press, Boca Raton

Wildenschild D, Sheppard AP (2013) X-ray imaging and analysis techniques for quantifying pore-scale structure and processes in subsurface porous medium systems. Adv Water Resour 51:217-246

Xu X, Schimel JP, Thornton PE, Song X, Yuan F, Goswami S (2014) Substrate and environmental controls on microbial assimilation of soil organic carbon: a framework for Earth system models. Ecol Lett 17(5):547-555

Yang X, Liu C, Shang J, Fang Y, Bailey VL (2014) A unified multiscale model for pore-scale flow simulations in soils. Soil Sci Soc Am J 78(1):108-118 